\title{
Duodenal microbiota composition and mucosal homeostasis in pediatric celiac disease
}

Jing Cheng ${ }^{1}$, Marko Kalliomäki ${ }^{2,3}$, Hans GHJ Heilig ${ }^{4}$, Airi Palva', Hannu Lähteenoja ${ }^{5}$, Willem M de Vos ${ }^{1,4,6}$, Jarkko Salojärvi ${ }^{1}$ and Reetta Satokari ${ }^{{ }^{*}}$

\begin{abstract}
Background: Celiac disease (CD) is an autoimmune disorder of the small intestine which is triggered by dietary gluten in genetically predisposed (HLA-DQ2/DQ8 positive) individuals. Only a fraction of HLA-DQ2/DQ8 positive individuals develop CD indicating that other factors have a role in the disorder. Several studies have addressed intestinal microbiota aberrancies in pediatric CD, but the results are inconsistent. Previously, we demonstrated that pediatric CD patients have lower duodenal expression of TLR2 and higher expression of TLR9 as compared to healthy controls $(\mathrm{HC})$ indicating that microbiota may have a role in $\mathrm{CD}$.

Methods: We used bacterial phylogenetic microarray to comprehensively profile the microbiota in duodenal biopsies of CD $(n=10)$ and HC $(n=9)$ children. The expression of selected mucosa-associated genes was assessed by qRT-PCR in $C D$ and $H C$ children and in treated $C D$ adults $(T-C D, n=6)$ on gluten free diet.

Results: The overall composition, diversity and the estimated microbe associated molecular pattern (MAMP) content of microbiota were comparable between $\mathrm{CD}$ and $\mathrm{HC}$, but a sub-population profile comprising eight genus-like bacterial groups was found to differ significantly between HC and CD. In HC, increased TLR2 expression was positively correlated with the expression of tight junction protein ZO-1. In CD and T-CD, the expression of IL-10, IFN-g and CXCR6 were higher as co5mpared to HC.

Conclusions: The results suggest that microbiota and altered expression of mucosal receptors have a role in CD. In CD subjects, the increased expression of IL-10 and IFN-g may have partly resulted from the increased TLR9 expression and signaling.
\end{abstract}

Keywords: Celiac disease, Microbiota, Gene expression, Duodenum, Host-microbe cross-talk

\section{Background}

Celiac disease (CD) is a common chronic immunemediated, inflammatory disorder of the small intestine induced by intolerance to gluten-containing dietary products $[1,2]$. When a $\mathrm{CD}$ patient consumes gluten, an inflammatory cascade occurs in the small intestinal mucosa, eventually resulting in an active disease that is characterized by villous atrophy, crypt hyperplasia and increased numbers of lymphocytes in the lamina propria $[1,3]$. Untreated $C D$ is manifested by gastrointestinal symptoms, malabsorption and even malnutrition [1,3] and also by extra-intestinal symptoms such as dermititis

\footnotetext{
* Correspondence: reetta.satokari@helsinki.fi

'Department of Veterinary Biosciences, University of Helsinki, P.O. Box 66, Helsinki Fl-00014, Finland

Full list of author information is available at the end of the article
}

herpetiformis (skin rash) in some individuals [3]. Both genetic predisposition and environmental factors are considered to be involved in the development of CD [4]. Individuals who carry the alleles human leukocyte antigen (HLA)-DQ2 or HLA-DQ8 have an increased risk of developing the disease, but only less than one tenth of them eventually get $\mathrm{CD}$, indicating that other genetic factors and/or environmental factors are also important in the pathogenesis [5]. Recently, 13 new CD risk loci were identified, bringing the number of known $C D$ loci to 40 and giving a refined picture of the genetic risk of CD [6]. Most of these loci contain candidate genes of immunological function, but the pathways leading from genetic predisposition to an affected person are poorly understood [6,7]. The intestinal microbiota is a major

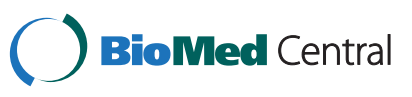


dictator of the antigen milieu of enterocytes, and it may have a role in the $\mathrm{CD}$ pathogenesis.

Gut colonization starts immediately after birth, and considerable microbiota maturation takes place during the first years of life followed by a gradual microbiota succession until young adulthood [8-10]. A balanced commensal microbiota contributes to the physiological development of the gut and the maturation of the immune system; thereby, alterations in the intestinal microbiota could play a role in the onset of different diseases, including $\mathrm{CD}[3,11]$. Increased bacterial diversity and changes in several bacterial groups in the microbiota of pediatric $C D$ patients have been reported in several studies [12-16]. However, other recent studies have failed to show major microbiota differences between children with and without CD [17-19]. Two recent studies have addressed the microbiota in infants with a genetic predisposition to $\mathrm{CD}[4,11]$. Both of these reported the microbiota of predisposed infants to be different from that of non-predisposed, but while Sellitto et al. reported a reduction or lack of Bacteroides in predisposed infants [4], De Palma et al. found that Bacteroides fragilis and staphylococci were increased and bifidobacteria were reduced in genetically susceptible infants [11]. Although the idea that the microbiota is involved in the etiology of $\mathrm{CD}$ has been addressed in numerous studies, the results on specific $\mathrm{CD}$-associated microbiota changes remain inconclusive.

Recently, we demonstrated that pediatric CD patients have decreased duodenal expression of Toll-like receptor 2 (TLR2) and the negative regulator of Toll-receptor signaling (Tollip), and increased expression of TLR9 and interleukin 8 (IL-8), which is a marker of intestinal inflammation [18]. TLRs are a family of pattern recognition receptors, which recognize conserved microbe-associated motifs such as lipopolysaccharides (LPS, ligand for TLR4), lipoproteins and lipoteichoeic acids (LTA, ligand for TLR2), flagellin (TLR5) and nucleic acid motifs (TLR3, 7 and 9). Intestinal epithelial homeostasis is dependent on the activation of TLRs at adequate levels in order to keep defense against microbes balanced and to avoid an excessive inflammatory response to gut commensals $[20,21]$. Further, TLR signaling is known to affect epithelial barrier function by having a bearing on the expression of tight junction proteins, mucus protein mucin 2 and antimicrobial peptides such as RegIII- $\gamma[20,21]$. Thus, our previous results suggested that microbiota may play a role in the etiology of $C D$, but we were unable to reveal aberrancies in the duodenal mucosal microbiota of pediatric $\mathrm{CD}$ by targeting selected bacterial groups by quantitative PCR (qPCR) [18].

The objectives of the present study were to comprehensively characterize the total duodenal mucosal microbiota and to re-evaluate the possible microbiota differences in pediatric $\mathrm{CD}$ patients and healthy controls by using a high-throughput bacterial phylogenetic microarray (HITChip). Further, the expression of nine mucosaassociated genes, IL-10, interferon-gamma (IFN- $\gamma$ ), tumor necrosis factor alpha (TNF- $\alpha$ ), a tight junction protein zonula occludens-1 (ZO-1), a gap junction protein connexin-43 (Cx43), a mucus protein mucin 2 (MUC2), an antimicrobial peptide RegIII $\gamma$, a chemokine CXCL16 and its receptor CXCR6 were measured by using a quantitative reverse transcription-PCR (qRT-PCR).

\section{Methods}

\section{Study subjects and DNA and RNA extraction}

Duodenal biopsy samples were collected from 20 Finnish children and 6 Finnish adults: 10 children with newly diagnosed CD (median age 9.5 $\pm 4.1 \mathrm{y} ; 3-14 \mathrm{y}, 4$ males and 6 females) before the implementation of gluten-free diet (GFD), 10 healthy control (HC) children (median age $8.5 \pm 3.8 \mathrm{y} ; 4-16 \mathrm{y}$, 4 males and 6 females) with gastrointestinal complaints or other reasons for esophagogastroduodenoscopy (abdominal pain - 4 patients, gastroesophageal reflux disease -2 patients, growth retardation -2 patients esophagitis -1 patient, achalasia -1 patient) and 6 adults (median age $46 \pm 11.4 \mathrm{y}$; 30-60 y) with $\mathrm{CD}$ who had been on a GFD at least for a year (treated CD, T-CD). All HC and T-CD subjects had both negative celiac serology and normal small intestinal mucosa (Marsh 0 lesions), while CD patients had both positive celiac serology markers (anti-tissue transglutaminase antibodies and/or antiendomysium antibodies) and villous atrophy and crypt hyperplasia (Marsh III lesions) in duodenal biopsy. The study subjects were the same as in our previous study [18] and the same DNA and RNA preparations were used in this study. The DNA and RNA extraction and purification protocols were described in detail earlier [18].

\section{Quantitative reverse-transcriptase-PCR (qRT-PCR)}

Gene expression assays were performed using comparative Ct (threshold cycle)-method with ABI 7300 Real Time PCR System. (Applied Biosystems/Life Technologies Corporation, Carlsbad, CA). Taqman Gene Expression Assays (Applied Biosystems) used in analyses were: IL-10, assay ID: Hs00174086_m1; IFN-g, assay ID: Hs00174143_m1; TNF- $\alpha$ assay ID: Hs00174128; ZO-1, assay ID: Hs01551861_m1; Cx43, assay ID: Hs00748 445_s1; MUC2, assay ID: Hs03005103_g1; RegIII $\gamma$, assay ID: Hs01595405_m1; CXCL16, assay ID: Hs0022 2859_m1; CXCR6, assay ID: Hs01890898_s1. Gene expression assays were performed according to kit's protocol. Reactions were run in three replicates in a total volume of $20 \mu \mathrm{l}$ or $50 \mu \mathrm{l}$ with $25 \mathrm{ng}$ of cDNA in each. Thermal cycler conditions used were 1) $50^{\circ} \mathrm{C}$ for $2 \mathrm{~min}$, 2) $95^{\circ} \mathrm{C}$ for $\left.10 \mathrm{~min}, 3\right) 95^{\circ} \mathrm{C}$ for $\left.15 \mathrm{sec}, 4\right) 60^{\circ} \mathrm{C}$ for $1 \mathrm{~min}$. Steps 3 and 4 were repeated 40 times. Gene 
expression of 18S rRNA was used as an endogenous control (a house-keeping gene) to normalize the gene expression. Negative control and Universe Human Reference RNA (Agilent Technologies, Santa Clara, CA) as a control RNA were included in every PCR run. Results were analyzed with RQ-Study program (Applied Biosystems) to receive $\mathrm{Ct}$ values for all samples. The relative expression of genes was then calculated as described in detail previously [18].

\section{Microbiota analysis by phylogenetic microarray}

The microbiota was analyzed with the bacterial phylogenetic microarray -the HITChip (Human Intestinal Tract Chip) [22-24]. This microarray consists of over 4. 800 oligonucleotide probes targeting the V1 and V6 hypervariable regions of the $16 \mathrm{~S}$ rRNA gene of 1038 intestinal phylotypes [22-24]. It allows a comprehensive and high-resolution analysis of the microbiota composition at different taxonomic levels. Genus-like level (L2) taxa correspond to bacteria having $90 \%$ or higher similarity in their 16S rRNA gene, whereas L1 taxa correspond to a phylum-like level [22].

The HITChip measurements were performed as previously described [22-24]. In brief, amplification of $16 \mathrm{~S}$ rRNA gene was carried out from 100-200 ng of DNA with primer T7 prom-Bact-27 F and Bact-1369R [25], followed by in vitro transcription, dye labeling, fragmentation, and hybridization, as described earlier [22]. The arrays were scanned with Agilent DNA Microarray Scanner G2505C (Agilent, USA) and the intensity values for each image were extracted from the generated images using Agilent Extraction Software, version 10.7.3.1. Normalization and quality control of HITChip array data were performed with scripts in R statistical software, as described earlier $[22,24,26]$. The technical replicates having a Pearson correlation over 0.94 were selected for further analysis and the replicates were averaged. The between sample normalization was carried out with min-max algorithm [27,28]. Signal intensity threshold was applied to reduce experimental and possible crosshybridization noise, as described previously [22].

\section{Estimation of the microbe associated molecular pattern (MAMP) content}

The relative content of selected MAMPs was estimated from the HITChip profiles summarizing the abundance of Gram-positive, Gram-negative or flagellated genuslike bacterial groups. The abundance of Gram-positive bacteria is assumed to reflect the load of LTA, i.e. TLR2 ligands, the abundance of Gram-negative bacteria the load of LPS i.e. TLR4 ligands, and the abundance of flagellated bacteria the load of TLR5 ligands. The general $\mathrm{GC} \%$ of the microbiome was estimated based on the genomic GC-content of representative species from each of the genus-like group (Additional file 1: Table S1), weighted by the relative abundance of each of these groups in the total microbiota. The GC\% is taken to reflect the load of unmethylated CpG motifs, i.e. TLR9 ligands, as a high GC content of a bacterial genome correlates with a higher number of CpG motifs in the genome (Kant R, de Vos WM, Palva A, Satokari R, unpublished results) $[29,30]$.

\section{Statistical analysis}

The data analysis was performed in $\mathrm{R}$ version 2.15 .1 ( $\mathrm{R}$ Development CT 2012). The sum of signal intensities for probes targeting a genus-like group was used as a quantitative measure of the abundance of the group in a sample [24]. When computing the signal at higher level taxa, the probe intensities were divided by the number of known target phylotypes per probe. The signal intensity above threshold was $\log 10$-transformed.

The diversity of the microbial profiles was computed by Simpson's reciprocal index of diversity (1/D) and Shannon indices on probe-level data [31,32]. Principal component analysis (PCA) and Redundancy analysis (RDA) [33,34] were computed using $R$ packages 'stats' and 'vegan'. The significance of separation in RDA was assessed with a permutation test [33] using 50000 permutations.

Bacterial groups that are associated with the health status were selected with 9-fold cross-validation (CV). The data was split into 9 subsets (folds) of equal size with stratification such that both $\mathrm{CD}$ and $\mathrm{HC}$ samples were present in all folds. In the $\mathrm{CV}$ procedure, eight subsets were used for training, and one subset in turn was left out for testing. Within each CV fold, six random forests were learned to predict the study group using a set of bacteria, selected by: i) choosing the $2,4,6,8$, or 10 bacteria having smallest p-values from two-sample $t$-test carried out within the training set, or ii) selecting the bacterial groups with high mean decrease in gini score from random forest using all bacteria [35]. The prediction error of the random forests was then estimated with the test data. The feature selection method with lowest prediction error rate from cross-validation (that is, 8 bacteria with smallest p-values) was then applied for the full data, and its prediction error was estimated with 9-fold cross validation. Significance of the prediction was tested with permutation test using 10,000 permutations.

Differentially present bacterial groups were analyzed with Student's $t$-test assuming two tailed distribution [36]. False discovery rate (FDR) correction of p-values was carried out using Benjamini-Hochberg (BH) correction [37]. The average relative abundance of each phylum- or genus-like group was estimated by first calculating the percentage of signal intensity within each 
sample, and then computing the average of percentage of signal intensities within $\mathrm{CD}$ and $\mathrm{HC}$ groups.

For relative gene expression, the normality of the data was tested by Shapiro-Wilk normality test function. When normality assumption applied, ANOVA and Tukey Honest Significant Differences post-hoc analysis was carried out. If the data residuals differed significantly from normality, Kruskal-Wallis and associated posthoc analysis were carried out [38]. For all analyses, FDR corrected pvalues below 0.05 were considered significant. The correlations between bacterial groups, gene expressions and MAMP content were estimated by Spearman coefficient, followed by FDR correction (BH) of p-value.

\section{Ethical considerations}

The study was accepted by the ethical committee of the Hospital District of Southwest Finland. Written informed consent was obtained from all of the study patients or their parents. Pediatric T-CD subjects could not be included as a control group in the study, because in Finland follow-up biopsies are not taken from children if celiac serology turns negative within two years after the implementation of GFD.

\section{Results}

\section{Composition of the duodenal mucosal microbiota}

HITChip microbiota profiles were obtained from $10 \mathrm{CD}$ subjects ( 4 males and 6 females) and 9 healthy controls (HC, median age $9 \pm 4.1$ years, 4 males and 5 females) (no significant difference in median age, one $\mathrm{HC}$ was not included due to a low reproducibility of HITChip profile, Additional file 2: Table S2).

At the bacterial phylum-like level, representatives from 13 groups were detected in the duodenal mucosa of the pediatric subjects (Table 1). The phylum-like level microbiota profiles were found to be individual-specific with large inter-individual variation (Figure 1). Proteobacteria, Bacilli and Bacteroidetes were found to be the major bacterial groups in the duodenal mucosa of both $\mathrm{CD}$ and HC (Figure 2). Proteobacteria and Bacilli constituted each approximately one third of the community while Bacteroidetes amounted to around 14\% (Figure 2). There were no significant differences in the abundance of bacterial phylum-like groups between CD and HC. Similarly, the bacterial diversity was comparable between the $\mathrm{HC}$ and $\mathrm{CD}$ groups (Figure 3).

Altogether 65 genus-like groups were detected in the duodenal biopsies (Table 1). HC and CD shared the same predominant genus-like groups, whose average proportion was above $5 \%$ of the total signal. The predominant groups were Sutterella wadsworthensis et rel., Streptococcus mitis et rel., Aquabacterium, Streptococcus bovis et rel., Streptococcus intermedius et rel., and Prevotella melaninogenica et rel. (Table 1). Among these, the most abundant bacterial groups in both $\mathrm{HC}$ and $\mathrm{CD}$ were Sutterella wadsworthensis et rel. and Streptococcus mitis et rel., both with an average abundance of 14 to 19\% (Table 1). No single genus-like bacterial group abundance differed significantly between $\mathrm{HC}$ and $\mathrm{CD}$ (Table 1).

\section{The general MAMP content of the duodenal microbiota}

The general MAMP content was estimated based on the microbiota profiles (Table 1). No significant difference between the abundance of Gram-positive or Gramnegative bacteria carrying LTA or LPS respectively was found, nor in the abundance of potentially flagellated bacteria between $\mathrm{HC}$ and $\mathrm{CD}$. Thus, the ligand load for TLR2, 4 and 5 seems comparable between $\mathrm{HC}$ and $\mathrm{CD}$. In addition, the average GC\% content of the total microbiota and the relative abundance of high-GC\% bacteria (genomic $\mathrm{GC} \%>58 \%$ ) were comparable between the groups suggesting a similar load of unmethylated $\mathrm{CpG}$ motifs, which are ligands for the TLR9.

\section{Celiac disease associated microbiota profile}

In PCA and RDA plots, $\mathrm{HC}$ vs. CD subjects did not cluster separately, showing that the groups do not differ in terms of the total microbiota profile (Additional file 3: Figure S1, Additional file 4: Figure S2). Moreover, as already mentioned above, no single genus-like bacterial group's abundance differed significantly between $\mathrm{HC}$ and CD (Table 1).

Further analysis was performed with random forests using feature selection as preprocessing step, where the best method was chosen from six candidates using crossvalidation. The aim was to identify a possible health status-related bacterial sub-population within the total microbiota. The feature selection method resulting in lowest cross-validated prediction error was to choose a set of eight genus-like bacteria having lowest $\mathrm{p}$-values from $t$-test (Figure 4). Thus, although no single genus-like group individually differed significantly between $\mathrm{HC}$ and $\mathrm{CD}$, a random forest learned with a profile of selected eight genus-like groups predicted the health status with error rate of $31.6 \%$. This is significantly better than random guess, having a median error rate of $53 \%$, and $95 \%$ confidence intervals of [32\%, 74\%].

As can be seen from Table 1, P. melaninogenica et rel. has a relative abundance of $5.3 \%$ and $6.5 \%$ in $\mathrm{HC}$ and $\mathrm{CD}$, respectively and it is among the predominant genus-like groups contributing to the separation between HC and CD. Also Haemophilus ssp. and Serratia ssp. had relatively higher abundance in $\mathrm{CD}$, whereas the other five bacterial groups were higher in $\mathrm{HC}$, see Table 1. 
Table 1 Composition of the duodenal mucosa-associated microbiota in healthy control (HC) and celiac disease (CD) children: the relative abundance of HITChip genus-like groups and MAMP content estimation

\begin{tabular}{|c|c|c|c|c|c|c|}
\hline \multirow[b]{2}{*}{ Phylum/Order } & \multirow[b]{2}{*}{ Genus-like phylogenetic group } & \multicolumn{2}{|c|}{ Relative abundance $(\%)^{*}$} & \multirow[b]{2}{*}{ Gram+/- } & \multirow[b]{2}{*}{ Flagella } & \multirow[b]{2}{*}{ GC\% } \\
\hline & & $\mathrm{HC}$ & $C D$ & & & \\
\hline \multirow[t]{2}{*}{ Actinobacteria } & Propionibacterium & $0.80 \pm 0.90$ & $1.43 \pm 1.31$ & G+ & $\mathrm{N}$ & 60 \\
\hline & Bifidobacterium & $0.52 \pm 0.60$ & $0.75 \pm 0.98$ & $\mathrm{G}+$ & N & 61 \\
\hline \multirow[t]{8}{*}{ Bacilli } & Streptococcus mitis et rel & $13.66 \pm 11.64$ & $19.35 \pm 12.95$ & $\mathrm{G}+$ & $\mathrm{N}$ & 40 \\
\hline & Streptococcus bovis et rel & $9.21 \pm 10.79$ & $5.72 \pm 3.99$ & $\mathrm{G}+$ & $\mathrm{N}$ & 37 \\
\hline & Streptococcus intermedius et rel & $6.38 \pm 5.00$ & $7.64 \pm 5.12$ & $\mathrm{G}+$ & $\mathrm{N}$ & 38 \\
\hline & Gemella & $1.47 \pm 2.27$ & $1.77 \pm 2.54$ & $\mathrm{G}+$ & $\mathrm{N}$ & 31 \\
\hline & Enterococcus & $0.28 \pm 0.33$ & $0.19 \pm 0.22$ & $\mathrm{G}+$ & $\mathrm{Y} / \mathrm{N}$ & 38 \\
\hline & Granulicatella & $0.24 \pm 0.27$ & $0.23 \pm 0.28$ & G+ & $\mathrm{N}$ & 37 \\
\hline & Bacillus & $0.17 \pm 0.46$ & $0.01 \pm 0.01$ & $\mathrm{G}+$ & $\mathrm{Y} / \mathrm{N}$ & 38 \\
\hline & Aerococcus & $0.16 \pm 0.19$ & $0.15 \pm 0.19$ & G+ & $\mathrm{N}$ & 41 \\
\hline \multirow[t]{14}{*}{ Bacteroidetes } & Prevotella melaninogenica et rel & $5.29 \pm 4.02$ & $6.51 \pm 9.75$ & G- & $\mathrm{N}$ & 41 \\
\hline & Allistipes et rel & $2.03 \pm 2.81$ & $2.02 \pm 3.37$ & G- & $\mathrm{N}$ & 55 \\
\hline & Parabacteroides distasonis et rel & $1.76 \pm 2.34$ & $1.21 \pm 2.23$ & G- & $\mathrm{N}$ & 45 \\
\hline & Bacteroides vulgatus et rel & $0.92 \pm 1.43$ & $0.47 \pm 0.88$ & G- & $\mathrm{N}$ & 42 \\
\hline & Tannerella et rel & $0.88 \pm 1.38$ & $0.60 \pm 1.08$ & G- & $\mathrm{N}$ & 47 \\
\hline & Bacteroides splachnicus et rel & $0.79 \pm 0.69$ & $1.60 \pm 2.73$ & G- & $\mathrm{N}$ & 43 \\
\hline & Prevotella tannerae et rel & $0.76 \pm 1.10$ & $0.51 \pm 0.64$ & G- & $\mathrm{N}$ & 47 \\
\hline & Prevotella oralis et rel & $0.32 \pm 0.29$ & $0.16 \pm 0.19$ & G- & $\mathrm{N}$ & 45 \\
\hline & Bacteroides intestinalis et rel & $0.32 \pm 0.49$ & $0.20 \pm 0.29$ & G- & $\mathrm{N}$ & 43 \\
\hline & Prevotella ruminicola et rel & $0.29 \pm 0.64$ & $0.11 \pm 0.14$ & G- & N & 48 \\
\hline & Bacteroides plebeius et rel & $0.25 \pm 0.30$ & $0.44 \pm 0.69$ & G- & $\mathrm{N}$ & 44 \\
\hline & Bacteroides stercoris et rel & $0.17 \pm 0.23$ & $0.06 \pm 0.07$ & G- & $\mathrm{N}$ & 46 \\
\hline & Bacteroides ovatus et rel & $0.16 \pm 0.23$ & $0.08 \pm 0.12$ & G- & $\mathrm{N}$ & 42 \\
\hline & Bacteroides fragilis et rel & $0.10 \pm 0.13$ & $0.15 \pm 0.28$ & G- & $\mathrm{N}$ & 44 \\
\hline Clostridium cl. I & Clostridia & $0.30 \pm 0.78$ & $0.01 \pm 0.01$ & $\mathrm{G}+$ & $\mathrm{Y} / \mathrm{N}$ & 26 \\
\hline Clostridium cl. III & Clostridium stercorarium et rel & $0.14 \pm 0.23$ & $0.03 \pm 0.08$ & G+ & Y & 39 \\
\hline \multirow[t]{8}{*}{ Clostridium Cl. IV } & Clostridium orbiscindens et rel & $1.14 \pm 1.69$ & $0.19 \pm 0.17$ & G+ & Y & 57 \\
\hline & Sporobacter termitidis et rel & $0.56 \pm 1.31$ & $0.11 \pm 0.18$ & G+ & Y & 57 \\
\hline & Clostridium leptum et rel & $0.50 \pm 1.07$ & $0.13 \pm 0.14$ & $\mathrm{G}+$ & $\mathrm{N}$ & 50 \\
\hline & Anaerotruncus colihominis et rel & $0.15 \pm 0.41$ & $4 \mathrm{E}-03 \pm 0.01$ & G+ & $\mathrm{N}$ & 54 \\
\hline & Ruminococcus callidus et rel & $0.14 \pm 0.29$ & $0.06 \pm 0.03$ & G+ & $\mathrm{N}$ & 43 \\
\hline & Eubacterium siraeum et rel & $0.14 \pm 0.40$ & $2 \mathrm{E}-03 \pm 0.01$ & G+ & $\mathrm{Y} / \mathrm{N}$ & 45 \\
\hline & Ruminococcus bromii et rel & $0.13 \pm 0.40$ & $6 \mathrm{E}-07 \pm 2 \mathrm{E}-06$ & G+ & $\mathrm{N}$ & 41 \\
\hline & Papillibacter cinnamivorans et rel & $0.13 \pm 0.28$ & $0.01 \pm 0.01$ & G+ & $\mathrm{N}$ & 56 \\
\hline Clostridium cl. IX & Veillonella & $2.36 \pm 1.78$ & $2.61 \pm 3.40$ & G- & $\mathrm{N}$ & 39 \\
\hline Clostridium cl. XI & Clostridium difficile et rel & $0.13 \pm 0.21$ & $0.06 \pm 0.02$ & $\mathrm{G}+$ & Y & 29 \\
\hline \multirow[t]{5}{*}{ Clostridium cl. XIVa } & Clostridium symbiosum et rel & $2.79 \pm 3.03$ & $3.86 \pm 2.51$ & G+ & Y & 46 \\
\hline & Ruminococcus obeum et rel & $1.79 \pm 2.28$ & $1.48 \pm 0.91$ & $\mathrm{G}+$ & $\mathrm{N}$ & 42 \\
\hline & Bryantella formatexigens et rel & $0.90 \pm 1.34$ & $0.24 \pm 0.11$ & G+ & $\mathrm{N}$ & 50 \\
\hline & Coprococcus eutactus et rel & $0.81 \pm 1.50$ & $0.21 \pm 0.16$ & G+ & $\mathrm{N}$ & 43 \\
\hline & Dorea formicigenerans et rel & $0.75 \pm 1.07$ & $0.25 \pm 0.13$ & G+ & $\mathrm{N}$ & 41 \\
\hline
\end{tabular}


Table 1 Composition of the duodenal mucosa-associated microbiota in healthy control (HC) and celiac disease (CD) children: the relative abundance of HITChip genus-like groups and MAMP content estimation (Continued)

\begin{tabular}{|c|c|c|c|c|c|c|}
\hline & Butyrivibrio crossotus et rel & $0.48 \pm 1.12$ & $0.08 \pm 0.09$ & $\mathrm{G}+$ & Y & 38 \\
\hline & Eubacterium rectale et rel & $0.47 \pm 0.76$ & $0.62 \pm 0.53$ & G+ & $\mathrm{Y} / \mathrm{N}$ & 41 \\
\hline & Ruminococcus gnavus et rel & $0.28 \pm 0.51$ & $0.09 \pm 0.04$ & G+ & $\mathrm{N}$ & 43 \\
\hline & Lachnospira pectinoschiza et rel & $0.26 \pm 0.33$ & $0.30 \pm 0.18$ & G+ & Y & 44 \\
\hline & Clostridium sphenoides et rel & $0.20 \pm 0.44$ & $0.09 \pm 0.17$ & $\mathrm{G}+$ & Y & 42 \\
\hline & Outgrouping Clostridium XIVa & $0.20 \pm 0.27$ & $0.21 \pm 0.18$ & $\mathrm{G}+$ & Y & 33 \\
\hline & Anaerostipes caccae et rel & $0.10 \pm 0.17$ & $0.07 \pm 0.09$ & $\mathrm{G}+$ & N & 44 \\
\hline Clostridium Cl. XV & Eubacterium limosum et rel & $0.21 \pm 0.61$ & $4 \mathrm{E}-03 \pm 0.01$ & G+ & $\mathrm{N}$ & 48 \\
\hline Clostridium cl. XVI & Solobacterium moorei et rel & $0.52 \pm 1.02$ & $0.04 \pm 0.11$ & G+ & $\mathrm{N}$ & 38 \\
\hline \multirow[t]{14}{*}{ Proteobacteria } & Sutterella wadsworthensis et rel & $19.16 \pm 13.81$ & $18.78 \pm 16.24$ & G- & $\mathrm{N}$ & 62 \\
\hline & Aquabacterium & $9.61 \pm 7.08$ & $9.45 \pm 9.20$ & G- & Y & 66 \\
\hline & Xanthomonadaceae & $1.93 \pm 2.96$ & $1.90 \pm 2.09$ & G- & Y & 61 \\
\hline & Moraxellaceae & $1.19 \pm 1.13$ & $1.33 \pm 1.06$ & G- & $\mathrm{N}$ & 42 \\
\hline & Vibrio & $0.86 \pm 0.54$ & $1.35 \pm 1.11$ & G- & Y & 47 \\
\hline & Escherichia coli et rel & $0.61 \pm 0.65$ & $0.50 \pm 0.33$ & G- & Y & 51 \\
\hline & Enterobacter aerogenes et rel & $0.60 \pm 0.90$ & $0.58 \pm 0.63$ & G- & Y & 55 \\
\hline & Burkholderia & $0.45 \pm 0.45$ & $0.56 \pm 0.47$ & G- & Y & 65 \\
\hline & Klebisiella pneumoniae et rel & $0.40 \pm 0.27$ & $0.74 \pm 0.50$ & G- & $\mathrm{N}$ & 57 \\
\hline & Oxalobacter formigenes et rel & $0.29 \pm 0.29$ & $0.29 \pm 0.33$ & G- & $\mathrm{N}$ & 51 \\
\hline & Haemophilus & $0.25 \pm 0.17$ & $0.46 \pm 0.31$ & G- & $\mathrm{N}$ & 39 \\
\hline & Pseudomonas & $0.22 \pm 0.15$ & $0.40 \pm 0.30$ & G- & Y & 65 \\
\hline & Proteus et rel & $0.17 \pm 0.27$ & $0.04 \pm 0.04$ & G- & Y & 38 \\
\hline & Serratia & $0.10 \pm 0.07$ & $0.20 \pm 0.15$ & G- & Y & 56 \\
\hline Uncult. Mollicutes & Uncultured Mollicutes & $0.20 \pm 0.49$ & $0.03 \pm 0.02$ & G- & $\mathrm{N}$ & 31 \\
\hline \multirow[t]{5}{*}{ Summary } & Proportion of Gram+ bacteria & $46.1 \pm 26.6$ & $45.4 \pm 25.5$ & & & \\
\hline & Proportion of Gram- bacteria & $52.5 \pm 26.7$ & $53.4 \pm 25.3$ & & & \\
\hline & Average GC\% content of microbiome & $48.6 \pm 5.8$ & $48.5 \pm 6.4$ & & & \\
\hline & Proportion of high-GC\% bacteria & $32.7 \pm 23.3$ & $33.3 \pm 27.0$ & & & \\
\hline & Propotion of flagellated bacteria & $20.4 \pm 8.2$ & $19.9 \pm 9.4$ & & & \\
\hline
\end{tabular}

*Relative abundance of the total microbiota (mean \pm standard deviation). No statistically significant differences in the abundance of individual genus-like bacterial groups between $\mathrm{HC}$ and $\mathrm{CD}$.

cl cluster, uncult uncultured, Gram + Gram positive bacteria, Gram- Gram negative bacteria, high-GC\% bacteria genomic GC\% content is more than 58\%,

$Y$ motile/flagellated, $N$ non-motile/non-flagellated, $Y / N$ motility variable (50\% of the group were taken to be flagellated).

\section{Human host gene expression}

The gene expression levels of ZO-1, CXCL16, CXCR6, IL-10, IFN- $\gamma$, TNF- $\alpha$, Cx43, MUC2, and RegIII $\gamma$ in duodenal biopsies were assessed by relative quantitative reverse transcription-PCR in the $\mathrm{HC}$ and $\mathrm{CD}$ children. Biopsies from six T-CD adults were included for comparison, because biopsies from T-CD children were not available (see ethical considerations above). The expression of ZO-1, CXCL16, CXCR6 could be assessed only from $8 \mathrm{HC}$ and $9 \mathrm{CD}$ subjects, because RNA of some of the samples did not suffice after the other qRT-PCR analysis (Figures 5 and 6).

The gene expression of $\mathrm{ZO}-1$ was decreased in $\mathrm{CD}$ as compared to T-CD (Figure 5). The expression of CXCR6 was higher in $\mathrm{CD}$ and T-CD as compared to HC (Figure 6A). The expressions of IL-10 and IFN- $\gamma$ were higher, whereas the ratio of IL-10 to IFN- $\gamma$ was significantly reduced in both $\mathrm{CD}$ and T-CD as compared to HC (Figure 7). The gene expressions of TNF- $\alpha$, Cx43, MUC2, RegIII $\gamma$ (Table $\mathrm{A} 2$ ), and CXCL16 (Figure 6B) were found to be comparable between the groups.

When correlating of TLR2 expression [18] with the expression of proteins related to the physical barrier function or the production of antimicrobial peptides ( $\mathrm{Cx} 43$, ZO-1, MUC2 and RegIII Y), the ZO-1 expression correlated positively with the TLR2 expression in the $\mathrm{HC}$ group $(\mathrm{p}=0.03$, rho $=0.88)$. The expression of $\mathrm{Cx} 43$ negatively correlated with the relative abundance of 


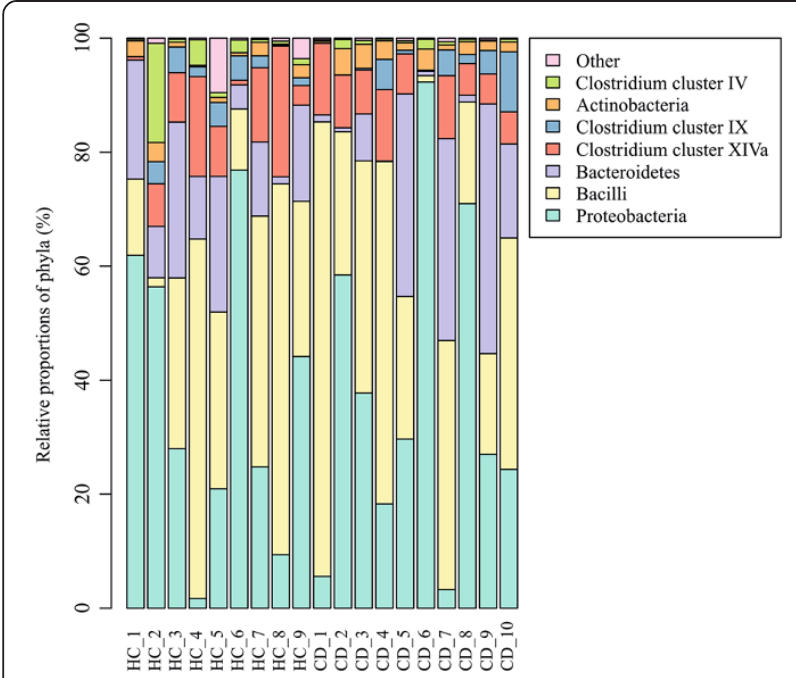

Figure 1 Composition of the duodenal mucosa-associated microbiota in healthy control (HC and celiac disease (CD) children. Relative proportions of bacterial phylum-like groups of the total microbiota are depicted for each individual (HC1-HC9 and CD1-CD10).

bacteria related to Solobacterium moorei (previously Bulleidia moorei) et rel. $(\mathrm{p}=0.03$, rho $=-0.82)$. No other correlations were found between the relative abundance of genus-like groups or the estimated MAMP content of the microbiota and the gene expressions (data not shown).

\section{Discussion}

Human small intestine, especially duodenum, is a distinctive environment for microbial life because of the excretion of digestive enzymes and bile, and it harbors a microbiota that is different from the one in the large

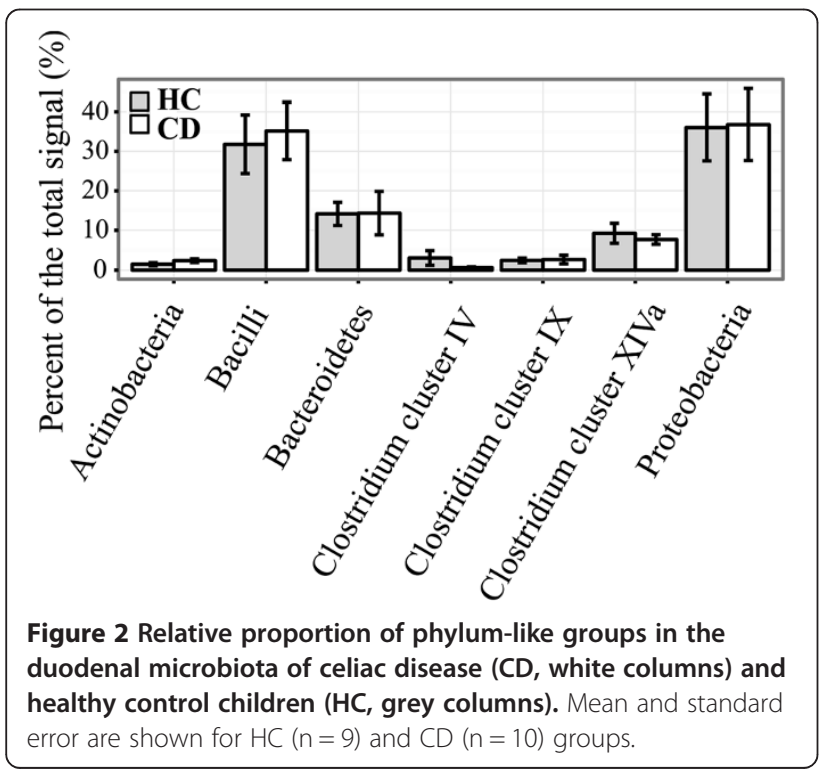

intestine [39]. The HITChip analysis showed that representatives of the genus Streptococcus constitute 29\% and $32 \%$ of the total duodenal microbiota in $\mathrm{HC}$ and $\mathrm{CD}$ subjects, respectively, and that the signal obtained for all Bacilli (phylum-like group) predominantly resulted from streptococci. This is in line with the previous findings $[39,40]$. In addition to Bacilli, Proteobacteria, Bacteroidetes and Clostridium cluster XIVa were found to be the most abundant phylum-like groups in the duodenum. These bacteria have previously been found to be dominant groups in the ileum, distal duodenum and proximal jejunum $[17,39,41]$ and in the duodenum [19]. Interestingly, within Proteobacteria a single most abundant genus-like group was found to be Sutterella wadsworthensis et rel. both in $\mathrm{CD}$ and $\mathrm{HC}$ subjects, which suggests that it belongs to the normal duodenal microbiota. Similarly, Mukhopadhya et al. detected $S$. wadsworthensis with an equally high frequency of 84 to $86 \%$ in the colonic biopsies of healthy adults $(n=64)$ or ulcerative colitis patients $(n=69)$, showing that the species belongs to the normal microbiota of intestinal mucosa and is unlikely to have a role in IBD [42]. Genus Aquabacterium belonging to the Proteobacteria also had a relatively high abundance $(\sim 9.5 \%$, prevalence $100 \%$ in both $\mathrm{CD}$ and $\mathrm{HC}$ ) in the duodenum of both groups of children. Previously, Aquabacterium has been detected in human colonic mucosal biopsy [43], but to our knowledge, this is the first time that Aquabacterium has been described as an abundant inhabitant of the human small intestine.

In the PCA and RDA analysis, $\mathrm{HC}$ and $\mathrm{CD}$ subjects did not cluster separately. Furthermore, none of the 65 genus-like bacterial groups was found to be significantly different in abundance between $\mathrm{HC}$ and $\mathrm{CD}$. Thus, the overall duodenal microbiota composition seems comparable between $\mathrm{HC}$ and $\mathrm{CD}$, which is in line with the results obtained by $\mathrm{Ou}$ et al [17] and Nistal et al [19] using small intestinal biopsies. Moreover, the bacterial diversity was also found to be comparable between the study groups. Previously, bacterial diversity assessed by PCR-T/DGGE has been observed to be increased in children with CD $[13,16]$. It is noteworthy that PCR-D /TGGE analysis detects only the most abundant bacteria and therefore may strongly underestimate microbiota diversity in complex communities. Our results from highthroughput microbiota profiling, like the results by Nistal et al [19], give a more in depth view of the duodenal microbiota regarding the bacterial groups inhabiting duodenal mucosa and the overall diversity. In addition, several studies have found differences in specific bacterial groups between HC and CD [12,14,15,44]. The most consistent findings from these studies were that children with CD have increased counts of Bacteroides and reduced counts of bifidobacteria either in feces 

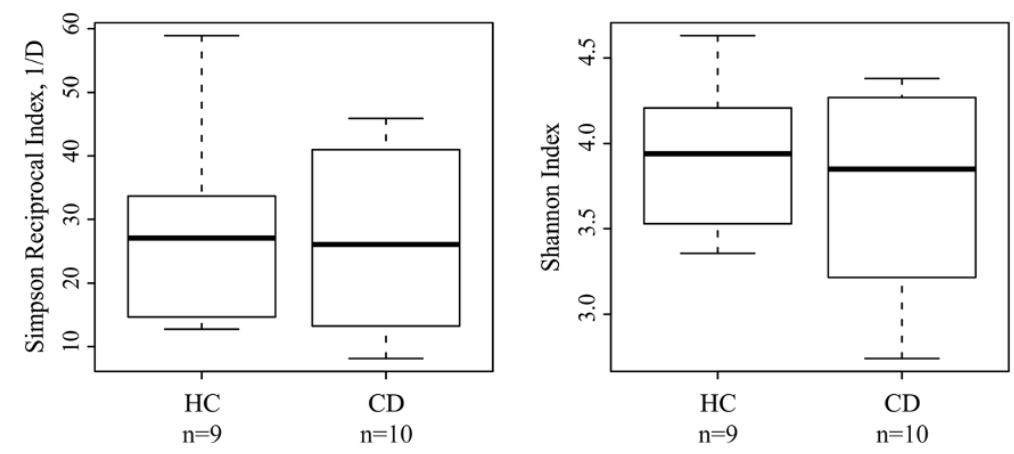

Figure 3 Duodenal microbiota diversity in healthy control $(H C, n=9)$ and celiac disease $(C D, n=10)$ children. The dominant/common species richness and evenness was assessed by Simpson Reciprocal (1/D) and overall species richness and evenness was assessed by Shannon Indices. Boxplot shows 25th to 75th percentile, with a line at median.

or duodenal epithelium $[12,14,15]$ which were not found to differ between $\mathrm{CD}$ and $\mathrm{HC}$ in this study.

As the overall microbiota profile, diversity or individual genus-like groups did not show a significant difference between $\mathrm{HC}$ and $\mathrm{CD}$, random forest was used to explore whether a sub-population bacterial profile could be associated with the health status. A profile of eight

A \begin{tabular}{l|ll|}
\hline $\begin{array}{l}\text { Prevotella melaninogenica et rel. } \\
\text { Haemophilus }\end{array}$ & & \\
Serratia & $\mathrm{CD}$ & \\
Prevotella oralis et rel. & & \\
Proteus et rel. & & \\
Clostridium stercorarium et rel. & $\mathrm{HC}$ & \\
Ruminococcus bromii et rel. & & \\
Papillibacter cinnamivorans et rel. & & \\
\hline
\end{tabular}

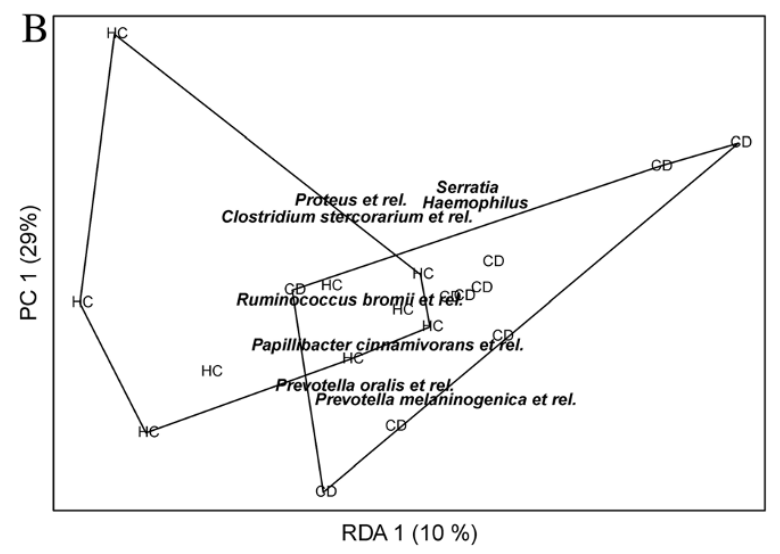

Figure 4 Sub-profile of the duodenal microbiota separating celiac disease (CD) and healthy control (HC) children. A) Eight HITChip genus-like level bacterial groups selected with random forest and cross-validation showing higher abundance in either HC (5 groups) or CD (3 groups). The error rate of random forest is $31.6 \%$, whereas $95 \%$ confidence intervals for random assignment are [32\%, 74\%]. B) The profile of eight bacterial groups separates healthy control children ( $\mathrm{HC})$ and celiac disease children (CD) in redundancy analysis (RDA). p-value obtained by permutation test (50000 permutations) is 0.050 . bacterial groups was found to distinguish $\mathrm{HC}$ from $\mathrm{CD}$. The abundance of Prevotella melaninogenica, and the total abundance of Prevotella spp (Table 1) were found to be higher in $C D$, which is in line with the results of $\mathrm{Ou}$ et al. [17] Haemophilus et rel. were also found to be enriched, although insignificantly as an individual bacterial group, in CD children by Nistal et al. [19]. Serratia spp. was also found to be present in higher abundance in $\mathrm{CD}$. The phylogenetic microarray targets mainly $S$. marcescens, which is considered as an opportunistic pathogen able to cause invasive infections (sepsis, meningitis, pneumonitis) in neonates $[45,46]$. These bacteria may impair the intestinal integrity, but their possible role in $\mathrm{CD}$ remains to be elucidated.

In the distinctive profile detected by random forest, $P$. oralis, R. bromii, P. cinnamivorans, Proteus and C. stercorarium groups are increased in the HC group. $R$. bromii is of particular interest, because it acts as key species for fiber/resistant starch degradation in the intestine [47] feeding butyrate producing bacteria including P. cinnamivorans [48]. Butyrate is a major source of energy to the enterocytes and acts as a regulator of gene expression, inflammation and differentiation in host cells [49]. Previously, R. bromii has been detected at increased level in healthy subjects as compared to Crohn's disease patients [50], indicating its potential role for benefiting the gut mucosal homeostasis.

Finally, it should be taken into account that the highly individual-specific microbiota-profiles may have a strong impact on the results within small study groups. Moreover, children in the HC group had healthy duodenal mucosa, but had gastrointestinal complaints or other reasons for gastroscopy and the possibility of microbiota alterations in these children as compared to children devoid of any symptoms can't be excluded. Therefore, the profile comprising eight genus-like bacterial groups, which showed significant difference between $C D$ and $\mathrm{HC}$ should be verified in future studies. 

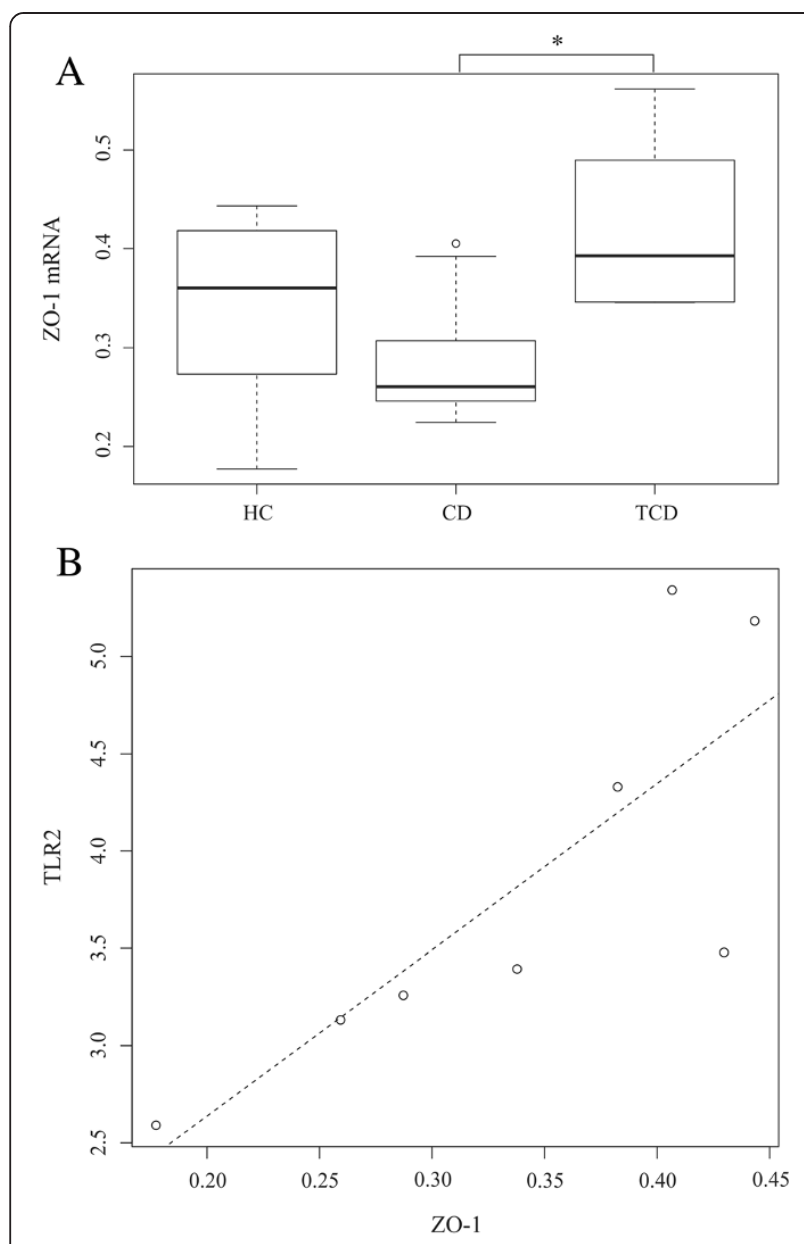

Figure 5 The relative expression of zonula occludens 1 (ZO-1) (A) and the scatterplot of ZO-1 and TLR2 expressions (B) in duodenal biopsies. A) Expression of ZO-1 in duodenal biopsies of healthy control children $(H C, n=8)$, celiac disease children $(C D, n=9)$ and treated celiac disease adults $(T-C D, n=6)$. The relative gene expression of ZO-1 is significantly between CD and T-CD $\left({ }^{*} p<0.05\right)$. Boxplot shows 25th to 75th percentile with a line at median and the whiskers represent interquartile range. Samples, which are outside 1.5 times the interquartile range above the upper quartile (3rd quartile) and below the lower quartile (1st quartile) are denoted by circles. B) The scatterplot of relative expression of ZO- 1 and TLR2 in duodenal biopsies of HC. The relationship between ZO-1 and TLR2 expressions is estimated by linear regression, and indicated by dashed line. The effect of slope is significant $(p=0.02)$, having coefficient of determination $\left(R^{2}\right)$ of 0.63 .

Similar average proportion of Gram-positive and Gramnegative bacteria, which are the carriers of LTA and LPS, respectively, was found in $\mathrm{CD}$ and $\mathrm{HC}$. Our previous findings from the same cohort showed that the expression of TLR2 is higher in HC [18]. As the LTA content is comparable between $\mathrm{HC}$ and $\mathrm{CD}$, the net signaling through TLR2 is presumably higher in HC. In vitro, TLR2 stimulation of intestinal epithelial cells (IECs) has been shown to increase $\mathrm{Cx} 43$ synthesis, the apical reorganization of ZO-1 and trans-epithelial resistance, which reflects the strength
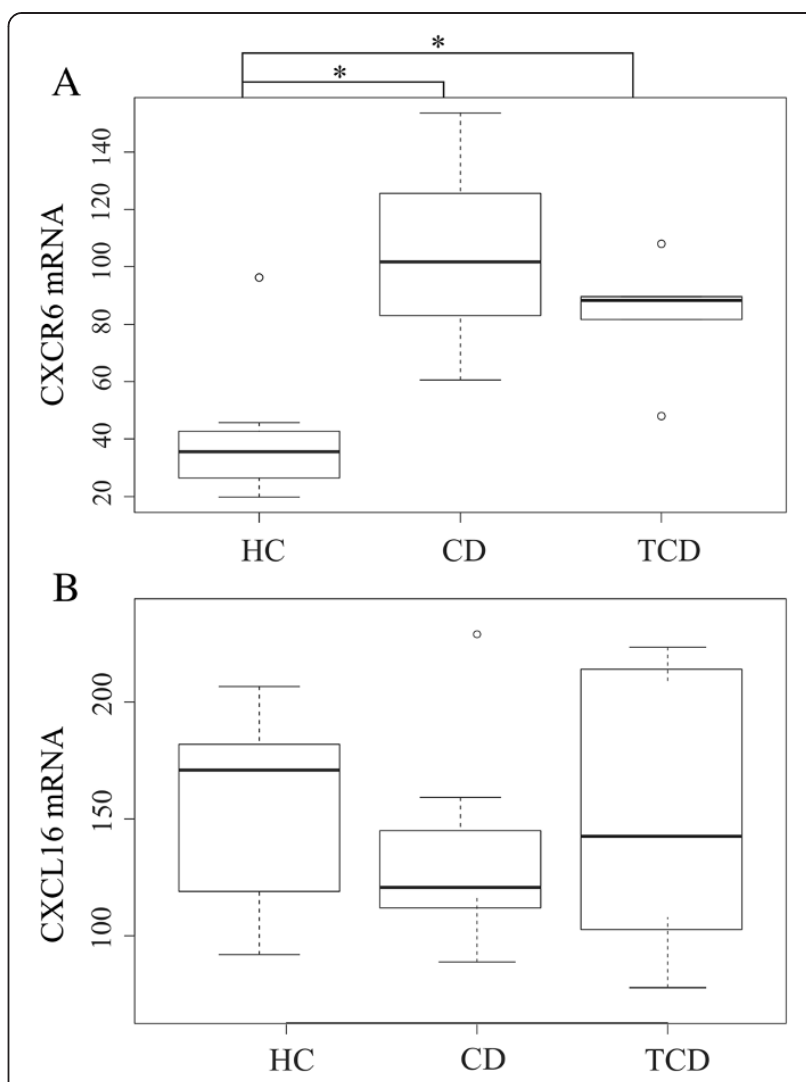

Figure 6 The relative expression of CXCL6 (A) and CXCR16 (B) in duodenal biopsies of healthy control children $(H C, n=8)$, celiac disease children $(C D, n=9)$ and treated celiac adults $(T-C D, n=6)$. Boxplot shows 25 th to 75 th percentile with a line at median and the whisker represents interquartile range. Samples, which are outside 1.5 times the interquartile range above the upper quartile (3rd quartile) and below the lower quartile (1st quartile) are denoted by circles. A) The difference in CXCR6 expression between $\mathrm{HC}$ and CD or T-CD is statistically significant $\left({ }^{*} \mathrm{p}<0.05\right)$. B) CXCL16 expression shows no significant differences between the groups.

of tight junctions between IECs and barrier function [51-53]. Although no significant difference was found in the expression $\mathrm{ZO}-1$ and $\mathrm{Cx} 43$ between $\mathrm{HC}$ and $\mathrm{CD}$, the expression of ZO-1 was significantly lower in $\mathrm{CD}$ as compared to T-CD. Moreover, there was a significant positive correlation between the expressions of ZO-1 and TLR2 in HC further supporting earlier findings, which demonstrated more permeable epithelial barrier in CD as compared to $\mathrm{HC}$ due to the decreased expression of tight junction proteins [54]. Negative correlation was found between the abundance of S. moorei et rel. and the expression of $\mathrm{Cx} 43$. Previously this bacterium has been associated with oral cavity diseases [55] and its possible down-regulatory effect of $\mathrm{Cx} 43$ may facilitate invasion and colonization. In CD, however, $S$. moorei et rel. seems to be irrelevant as it was found to be as abundantly present in $\mathrm{HC}$ and $\mathrm{CD}$. 

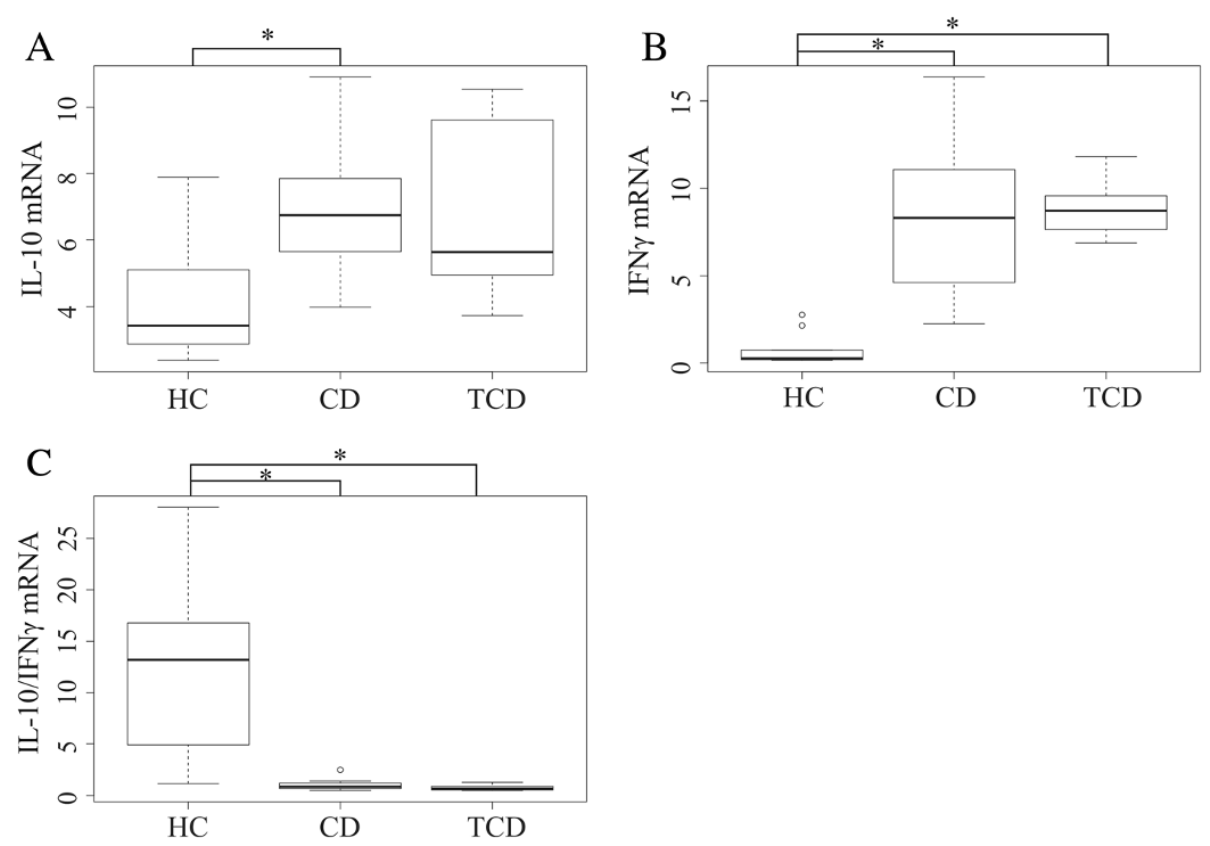

Figure 7 The relative expression of interleukin-10 (IL-10) (A), interferon gamma (IFNץ) (B) and IL-10 to IFN $\gamma$ mRNA ratio (C) in duodenal biopsies of healthy control children $(H C, n=10)$, celiac disease children $(C D, n=10)$ and treated celiac adults $(T-C D, n=6)$. Boxplot shows 25th to 75th percentile with a line at median and the whisker represents interquartile range. Samples which are outside 1.5 times the interquartile range above the upper quartile (3rd quartile) and below the lower quartile (1st quartile) are denoted by circles. A) IL-10 expression is significantly different between HC and CD. B) IFNy expression is significantly different between HC and CD or T-CD. C) The ratio of IL-10/IFNy expression is significantly different between HC and CD or T-CD. The significance between study groups: ${ }^{*} p<0.05$.

CXCL16 has been shown to function as a scavenger receptor in antigen-presenting cells where it mediates adhesion and phagocytosis of both Gram-positive and Gram-negative bacteria [56]. In addition, it works as a chemokine for CXCR6-expressing cells such as natural killer T cells and T helper 1 (Th1) - polarized CD4 T cells [57]. Since both microbiota alterations and Th1-polarized inflammation have been linked to the pathogenesis of celiac disease, we decided to evaluate the expression of both CXCL16 and its receptor CXCR6 in this study. We found that the expression of cytokine CXCL16 was found to be comparable in $\mathrm{CD}$ and $\mathrm{HC}$ and $\mathrm{T}-\mathrm{CD}$, whereas the expression of its receptor CXCR6 was higher in CD and T-CD as compared to HC. CXCL16 has dual functions as a transmembrane adhesion molecule and a soluble chemokine [58]. Both the membrane-bound form of CXCL16 and its receptor CXCR6 have been found to be expressed not only by dendritic cells/macrophages and $\mathrm{T}$ cells respectively, but also by IECs [58-60]. Previously, increased intestinal CXCL16 expression has been observed in the colonic biopsies of Crohn's disease patients due to immune cell infiltration [60]. In this study, an increased expression of CXCR6 was not only observed in the inflamed mucosa of CD but also in T-CD without immune cell infiltration suggesting an altered expression in epithelial cells. However, increased expression of CXCR6 in mucosa associated immune cells cannot be excluded when studying whole biopsies with different cell types. Diegelmann et al observed that in vitro stimulation of CXCR6 activates several distinct signaling pathways in IECs and they suggested that the CXCL16-CXCR6 chemokine-receptor system contributes to the integrity of epithelium and the regulation of mucosal innate and adaptive immune systems [60]. To our knowledge our data report for the first time an increased duodenal expression of CXCR6 in CD subjects in whom it may have an important role in the mucosal immunity.

The average genomic GC content (GC\%) of the total microbiota and the proportion of high-GC\% bacteria was found to be comparable between the $\mathrm{HC}$ and $\mathrm{CD}$ groups. High GC content of a bacterial genome correlates with a higher number of potentially immunostimulatory CpG motifs in the genome (Kant R, de Vos WM, Palva A, Satokari R, unpublished results) $[29,30]$ and thus, the GC\% was taken to reflect the load of TLR9 ligands in the microbiota. Consequently, $\mathrm{HC}$ and $\mathrm{CD}$ are likely to harbor similar load of TLR9 ligands. Our previous results from the same cohort showed that the expression of TLR9 in duodenum is higher in CD [18]. Thus, the signaling through TLR9 is presumably higher 
in $\mathrm{CD}$ as compared to $\mathrm{HC}$ due to the equally high load of TLR9 ligands and higher expression of TLR9. In immune cells, TLR9 stimulation is known to trigger Th1 type immune responses [61-63]. Further, a recent in vitro study demonstrated that apical TLR9 stimulation of IECs leads to an increased expression of IFN- $\gamma$ and IL-10, but not TNF- $\alpha$ from peripheral blood mononuclear cells (PBMCs) on the basolateral side [64]. In CD patients, increased mucosal expression of IL-10 and IFN- $\gamma$ is well documented and has been associated with the activity of gliadin-reactive T-cells upon the gluten/ gliadin stimulation either in vivo or in vitro [65-69]. We found that the expression of IL-10 and IFN- $\gamma$ in the duodenal mucosa was increased not only in CD but also in T-CD with gluten-free diet, suggesting for an additional gluten/gliadin-independent route of stimulation. Similarly to previous studies $[65,68,69]$, TNF- $\alpha$ expression was found to be unaffected in $\mathrm{CD}$ and $\mathrm{T}-\mathrm{CD}$ as compared to $\mathrm{HC}$. The ratio of IL-10 to IFN- $\gamma$ transcripts was strongly reduced in both $\mathrm{CD}$ and T-CD as compared to $\mathrm{HC}$ suggesting that although IL-10 expression was also increased there is a significant inclination towards a Th1 response both in untreated and treated CD. Since both CD and T-CD had increased expression of TLR9 [18], we hypothesize that the increased TLR9 signaling in the small intestine may contribute to the persistent activation of Th1 (IFN- $\gamma$ ) signaling pathway markers in the small intestine found in CD children despite gluten-free diet treatment [70]. Due to the limitations in studying whole biopsies with different cell types we cannot conclude which of the proposed signaling routes i.e. the direct TLR9 stimulation of immune cells or the stimulation of IECs with subsequent triggering of immune cells would possibly encompass more into the observed cytokine profile.

\section{Conclusions}

Our results suggest that intestinal microbiota and hostmicrobe cross-talk play a role in the CD. While the overall microbiota composition in the duodenal mucosa was comparable between the $\mathrm{CD}$ and healthy children, a sub-population profile comprising eight genus-like bacterial groups was found to differ significantly between the study groups. The sub-population of bacteria has potentially a specific role in e.g. maintaining gut homeostasis in the healthy individuals or in compromising the epithelial function in CD. Secondly, these and our previous results from the same cohort [18] suggest that altered expression of mucosal receptors and epithelial host-microbe cross-talk have a role in CD. We hypothesize that increased TLR9 signaling in the duodenum may contribute to the Th1 response (increased IFN- $\gamma$ ) found in the small intestinal mucosa of CD subjects even after the implementation of GFD.

\section{Additional files} Additional file 1: Table S1. Properties of HITChip genus-like groups.
Cell wall type (Gram+/Gram-), presence of flagella and the genomic GC\% were used for the estimation of microbe associated molecular pattern (MAMP) content in the total microbiota.

Additional file 2: Table S2. The duodenal expression levels of nine mucosa-associated genes in celiac disease (CD) and healthy control (HC) children and in treated CD adults (T-CD). Table indicates also from which subjects reproducible HITChip bacterial microarray profiles were obtained.

Additional file 3: Figure S1. Principal component analysis (PCA) of the duodenal microbiota profiles from healthy control $(H C, n=9)$ and celiac disease $(C D, n=10)$ children at the HITChip genus-like level. The first two principal components capture $35 \%$ and $21 \%$ of variance, respectively.

Additional file 4: Figure S2. Redundancy analysis (RDA) of duodenal microbiota profiles from healthy control $(\mathrm{HC}, \mathrm{n}=9)$ and celiac disease ( $n=10)$ children at HITChip genus-like level. The separation is not significant $(p=0.41)$.

\section{Abbreviations}

BH: Benjamini-Hochberg; CD: Celiac disease; CV: Cross validation; CX43: Connexin-43; CXCR6: Chemokine (C-X-C motif) receptor 6; CXCL16: Chemokine (C-X-C motif) ligand 16; et rel: And relatives; FDR: False discovery rate; GFD: Gluten-free diet; HC: Healthy control; HITChip: Human intestinal tract chip; HLA: Human leukocyte antigen; IECs: Intestinal epithelial cells; IFN-ү: Interferon gamma; IL: Interleukin; LPS: Lipopolysaccharide; LTA: Lipoteichoeic acid; MAMP: Microbe associated molecular pattern; MUC2: Mucin 2; PBMCs: Peripheral blood mononuclear cells; PCA: Principal component analysis; qPCR: Quantitative PCR; RDA: Redundancy analysis; T-CD: Treated celiac disease; TLR: Toll-like receptor; TNF-a: Tumor necrosis factor alpha; ZO-1: Zonula occludens-1.

\section{Competing interests}

The authors declare that they have no competing interest.

\section{Authors' contributions}

Study concept and design: MK, WdV, RS; collection of clinical samples: MK, $\mathrm{HL}$; acquisition of data: JC, MK, HH, HL, RS; analysis and interpretation of data: JC, MK, HH, JS, RS; statistical analysis: JC, JS; drafting of the manuscript: JC, MK, RS; critical reading and revision of the manuscript: JC, MK, AP, WdV, JS, RS; obtained funding: MK, AP, RS; administrative: MK, AP, RS; study supervision: MK, JS, RS. All authors read and approved the final version for publication.

\section{Acknowledgements \\ Riikka Lankinen is acknowledged for technical assistance. The financial support from the Academy of Finland (grant nr. 138902), the Finnish Medical Foundation, the Paediatric Research Foundation, the Hospital District of Southwest Finland, the Finnish Coeliac Society, and the Center of Excellence in Microbial Food Safety (CoE-MiFoSa) research program of the Academy of Finland are gratefully acknowledged.}

\section{Author details}

${ }^{1}$ Department of Veterinary Biosciences, University of Helsinki, P.O. Box 66, Helsinki Fl-00014, Finland. ${ }^{2}$ Department of Pediatrics, University of Turku and Turku University Central Hospital, P.O. Box 52, Turku 20521, Finland. ${ }^{3}$ Functional Foods Forum, 20014 University of Turku, Turku, Finland. ${ }^{4}$ Laboratory of Microbiology, Wageningen University, Dreijenplein 10, Wageningen 6703 HB, The Netherlands. 'Department of Internal Medicine, Turku University Central Hospital, P.O. Box 52, Turku 20521, Finland.

${ }^{6}$ Haartman Institute, University of Helsinki, P.O. Box 21, Helsinki Fl-00014, Finland.

Received: 19 April 2013 Accepted: 8 July 2013 Published: 11 July 2013

\section{References}

1. Green P, Jabri B: Celiac disease. Annu Rev Med 2006, 57:207-221. 
2. Papista C, Gerakopoulos V, Kourelis A, Sounidaki M, Kontana A, Berthelot L, Moura IC, Monteiro RC, Yiangou M: Gluten induces coeliac-like disease in sensitised mice involving $\lg A, C D 71$ and transglutaminase 2 interactions that are prevented by probiotics. Lab Invest 2012, 92:625-635.

3. Soni S, Badawy SZA: Celiac disease and its effect on human reproduction a review. J Reprod Med 2010, 55:3-8.

4. Sellitto M, Bai G, Serena G, Fricke WF, Sturgeon C, Gajer P, White JR, Koenig SSK, Sakamoto J, Boothe D, Gicquelais R, Kryszak D, Puppa E, Catassi C, Ravel J, Fasano A: Proof of concept of microbiome-metabolome analysis and delayed gluten exposure on celiac disease autoimmunity in genetically at-risk infants. PLoS One 2012, 7:e33387.

5. Trynka G, Wijmenga C, van Heel DA: A genetic perspective on coeliac disease. Trends Mol Med 2010, 16:537-550.

6. Trynka G, Hunt KA, Bockett NA, Romanos J, Mistry V, Szperl A, Bakker SF, Bardella MT, Bhaw-Rosun L, Castillejo G, de la Concha EG, de Almeida RC, Dias KRM, van Diemen CC, Dubois PCA, Duerr RH, Edkins S, Franke L, Fransen K, Gutierrez J, Heap GAR, Hrdlickova B, Hunt S, Plazalzurieta L, Izzo V, Joosten LAB, Langford C, Mazzilli MC, Mein CA, Midah V, et al: Dense genotyping identifies and localizes multiple common and rare variant association signals in celiac disease. Nat Genet 2011, 43:1193-1201.

7. Sperandeo MP, Tosco A, Izzo V, Tucci F, Troncone R, Auricchio R, Romanos J, Trynka F, Auricchio S, Jabri B, Greco L: Potential celiac patients: a model of celiac disease pathogenesis. PLoS One 2011, 6:e21281.

8. Palmer C, Bik EM, DiGiulio DB, Relman DA, Brown PO: Development of the human infant intestinal microbiota. PLOS Biol 2007, 5:e177.

9. Nylund L, Satokari R, Nikkilä J, Rajilic-Stojanovic M, Kalliomäki M, Isolauri E, Salminen S, de Vos WM: Microarray analysis reveals marked intestinal microbiota aberrancy in infants having eczema compared to healthy children in at-risk for atopic disease. BMC Microbiol 2013, 13:12.

10. Yatsunenko T, Rey FE, Manary MJ, Trehan I, Dominguez-Bello MG, Contreras M, Magris M, Hidalgo G, Baldassano RN, Anokhin AP, Heath AC, Warner B, Reeder J, Kuczynski J, Caporaso JG, Lozupone CA, Lauber C, Clemente JC, Knights D, Gordon II: Human gut microbiome viewed across age and geography. Nature 2012, 486:222-227.

11. De Palma G, Capilla A, Nova E, Castillejo G, Varea V, Pozo T, Antonio GJ, Polanco I, Lopez A, Ribes-Koninckx C, Marcos A, Dolores GNM, Calvo C, Ortigosa L, Pena-Quintana L, Palau F, Sanz Y: Influence of milk-feeding type and genetic risk of developing coeliac disease on intestinal microbiota of infants: the PROFICEL study. PLoS One 2012, 7:e30791.

12. Nadal I, Donant E, Ribes-Koninckx C, Calabuig M, Sanz Y: Imbalance in the composition of the duodenal microbiota of children with coeliac disease. J Med Microbiol 2007, 56:1669-1674

13. Sanz Y, Sanchez E, Marzotto M, Calabuig M, Torriani S, Dellaglio F: Differences in faecal bacterial communities in coeliac and healthy children as detected by PCR and denaturing gradient gel electrophoresis. FEMS Immunol Med Microbiol 2007, 51:562-568.

14. Collado MC, Donat E, Ribes-Koninckx C, Calabuig M, Sanz Y: Specific duodenal and faecal bacterial groups associated with paediatric coeliac disease. J Clin Pathol 2009, 62:264-269.

15. De Palma G, Nadal I, Medina M, Donat E, Ribes-Koninckx C, Calabuig M, Sanz Y: Intestinal dysbiosis and reduced immunoglobulin-coated bacteria associated with coeliac disease in children. BMC Microbio/ 2010, 10:63.

16. Schippa S, lebba V, Barbato M, Di Nardo G, Totino V, Checchi MP, Longhi C, Maiella G, Cucchiara S, Conte MP: A distinctive 'microbial signature' in celiac pediatric patients. BMC Microbiol 2010, 10:175

17. Ou G, Hedberg M, Hörstedt P, Baranov V, Forsberg G, Drobni M, Sandström O, Wai SN, Johansson I, Hammarström ML, Hernell O, Hammarström S: Proximal small intestinal microbiota and identification of rod-shaped bacteria associated with childhood celiac disease. Am J Gastroenterol 2009, 104:3058-3067.

18. Kalliomäki M, Satokari R, Lähteenoja H, Vähämiko S, Grönlund J, Routi T, Salminen S: Expression of microbiota, Toll-like receptors, and their regulators in the small intestinal mucosa in celiac disease. $J$ Pediatr Gastroenterol Nutr 2012, 54:727-732.

19. Nistal E, Caminero A, Herran AR, Arias L, Vivas S, Ruiz de Morales JM, Jose M, Calleja S, Saenz De M, Luis E, Arroyo P, Casqueiro J: Differences of small intestinal bacteria populations in adults and children with/without celiac disease: effect of age, gluten diet, and disease. Inflamm Bowel Dis 2012, 18:649-656.

20. Maynard $\mathrm{CL}$, Elson $\mathrm{CO}$, Hatton $\mathrm{RD}$, Weaver $\mathrm{CT}$ : Reciprocal interactions of the intestinal microbiota and immune system. Nature 2012, 489:231-241.
21. Abreu MT: Toll-like receptor signalling in the intestinal epithelium: how bacterial recognition shapes intestinal function. Nat Rev Immunol 2010, 10:131-144

22. Rajilic-Stojanovic M, Heilig HGHJ, Molenaar D, Kajander K, Surakka A, Smidt $H$, de Vos WM: Development and application of the human intestinal tract chip, a phylogenetic microarray: analysis of universally conserved phylotypes in the abundant microbiota of young and elderly adults. Environ Microbiol 2009, 11:1736-1751.

23. Biagi E, Nylund L, Candela M, Ostan R, Bucci L, Pini E, Nikk J, Monti D, Satokari R, Franceschi C, Brigidi P, De Vos W: Through ageing, and beyond: gut microbiota and inflammatory status in seniors and centenarians. PLoS One 2010, 5:e10667.

24. Jalanka-Tuovinen J, Salonen A, Nikkilä J, Immonen O, Kekkonen R, Lahti L, Palva A, de Vos WM: Intestinal Microbiota in Healthy Adults: Temporal Analysis Reveals Individual and Common Core and Relation to Intestinal Symptoms. PLoS One 2011, 6:e23035. doi:10.1371/journal. pone.0023035.

25. Iwamoto T, Tani K, Nakamura K, Suzuki Y, Kitaqawa M, Equchi M, Nasu M: Monitoring impact of in situ biostimulation treatment on groundwater bacterial community by DGGE. FEMS Microbiol Ecol 2000, 32:129-141.

26. Salonen A, Nikk J, Jalanka-Tuovinen J, Immonen O, Rajilic-Stojanovic M, Kekkonen RA, Palva A, de Vos WM: Comparative analysis of fecal DNA extraction methods with phylogenetic microarray: effective recovery of bacterial and archaeal DNA using mechanical cell lysis. J Microbiol Methods 2010, 81:127-134.

27. Bolstad B, Irizarry R, Astrand M, Speed T: A comparison of normalization methods for high density oligonucleotide array data based on variance and bias. Bioinformatics 2003, 19:185-193.

28. Han JKM: Data mining: concepts and techniques. San Francisco, CA: Morgan Kaufmann Publishers; 2006

29. Menard O, Gafa V, Kapel N, Rodriguez B, Butel M, Waligora-Dupriet A: Characterization of immunostimulatory $\mathrm{CpG}$-rich sequences from different Bifidobacterium species. Appl Environ Microbiol 2010, 76:2846-2855.

30. Lee KW, Jung JW, Lee Y, Kim TY, Choi SY, Park J, Kim DS, Kwon HJ: Immunostimulatory oligodeoxynucleotide isolated from genome wide screening of Mycobacterium bovis chromosomal DNA. Mol Immunol 2006, 43:2107-2118.

31. Simpson E: Measurement of diversity. Nature 1949, 163:688-688.

32. Hill MO: Diversity and evenness - a unifying notation and its consequences. Ecology 1973, 54:427-432

33. Legendre PLL: Numerical Ecology. Amsterdam, NL: Elservier Science BV; 1998.

34. Venables WNRB: Modern applied statistics with S. New York, NY: Springer; 2002.

35. Breiman L: Random forests. Mach Learn 2001, 45(1):5-32.

36. Chambers JM, Hastie TJ: Statistical models in S. Pacific Grove, CA: Wasdsworth \& Brooks/Cole; 1992.

37. Benjamini Y, Drai D, Elmer G, Kafkafi N, Golani I: Controlling the false discovery rate in behavior genetics research. Behav Brain Res 2001, 125:279-284.

38. Siegel S, Castellan NJ: Non parametric statistics for the behavioural sciences. New York, NY: MacGraw-Hill; 1988.

39. Zoetendal EG, Raes J, van de Bogert B, Arumugam M, Booijink CC, Troost FJ, Bork P, Wels M, de Vos WM, Kleerebezem M: The human small intestinal microbiota is driven by rapid uptake and conversion of simple carbohydrates. ISME J 2012, 6:1415-1426.

40. Sullivan A, Tornblom H, Lindberg G, Hammarlund B, Palmgren AC, Einarsson C, Nord CE: The micro-flora of the small bowel in health and disease. Anaerobe 2003, 9:11-14.

41. Ricanek P, Lothe SM, Frye SA, Rydning A, Catn MH, Tønjum T: Gut bacterial profile in patients newly diagnosed with treatment-naive Crohn's disease. Clin Exp Gastroenterol 2012, 5:173-186.

42. Mukhopadhya I, Hansen R, Nicholl CE, Alhaidan YA, Thomson JM, Berry SH, Pattinson C, Stead DA, Russell RK, El-Omar EM, Hold GL: A comprehensive evaluation of colonic mucosal isolates of Sutterella wadsworthensis from inflammatory bowel disease. PLoS One 2011, 6:e27076.

43. Wang X, Heazlewood SP, Krause DO, Florin TH: Molecular characterization of the microbial species that colonize human ileal and colonic mucosa by using 16S rDNA sequence analysis. J App/ Microbiol 2003, 95:508-520.

44. Sanchez E, Donat E, Ribes-Koninckx C, Calabuig M, Sanz Y: Intestinal Bacteroides species associated with coeliac disease. J Clin Pathol 2010, 63:1105-1111 
45. Polilli E, Parruti G, Fazii P, D'Antonio D, Palmieri D, D'Incecco C, Mangifesta A, Garofalo G, Del Duca L, D'Amario C, Scimia M: Rapidly controlled outbreak of Serratia marcescens infection/colonisations in a neonatal intensive care unit, Pescara General Hospital, Pescara, Italy. Eurosurveillance 2011, 16:16-18.

46. Adamson V, Mitt $P$, Pisarev $H$, Metsvaht $T$, Telling $K$, Naaber $P$, Maimets $M$ : Prolonged outbreak of Serratia marcescens in Tartu University Hospital: a case-control study. BMC Infect Dis 2012, 12:281.

47. Ze X, Duncan SH, Louis P, Flint HJ: Ruminococcus bromii is a keystone species for the degradation of resistant starch in the human colon. ISME J 2012, 6:1535-1543.

48. Defnoun S, Labat M, Ambrosio M, Garcia JL, Patel BKC: Papillibacter cinnamivorans gen. nov., sp nov., a cinnamate-transforming bacterium from a shea cake digester. Int J Syst Evol Microbiol 2000, 50:1221-1228.

49. Flint HJ, Scott KP, Louis P, Duncan SH: The role of the gut microbiota in nutrition and health. Nat Rev Gastroenterol Hepatol 2012, 9:577-589.

50. Mondot S, Kang S, Furet JP, de Carcer DA, McSweeney C, Morrison M, Marteau P, Dore J, Leclerc M: Highlighting new phylogenetic specificities of Crohn's disease microbiota. Inflamm Bowel Dis 2011, 17:185-192.

51. Cario E, Gerken G, Podolsky DK: Toll-like receptor 2 enhances ZO-1 -associated intestinal epithelial barrier integrity via protein kinase $C$. Gastroenterology 2004, 127:224-238.

52. Cario E, Gerken G, Podolsky DK: Toll-like receptor 2 controls mucosal inflammation by regulating epithelial barrier function. Gastroenterology 2007, 132:1359-1374.

53. Ey B, Eyking A, Gerken G, Podolsky DK, Cario E: TLR2 mediates gap junctional intercellular communication through connexin-43 in intestinal epithelial barrier injury. J Biol Chem 2009, 284:22332-22343.

54. Pizzuti D, Bortolami M, Mazzon E, Buda A, Guariso G, D'Odorico A, Chiarelli S, D'Inca R, De Lazzari F, Martines D: Transcriptional downregulation of tight junction protein ZO-1 in active coeliac disease is reversed after a gluten-free diet. Dig Liver Dis 2004, 36:337-341.

55. Pedersen RM, Holt HM, Justesen US: Solobacterium moorei bacteremia: identification, antimicrobial susceptibility, and clinical characteristics. J Clin Microbiol 2011, 49:2766-2768.

56. Shimaoka T, Nakayama T, Kume N, Takahashi S, Yamaguchi J, Minami M, Hayashida K, Kita T, Ohsumi J, Yoshie O, Yonehara S: Cutting edge: SRPSOX/CXC chemokine ligand 16 mediates bacterial phagocytosis by APCs through its chemokine domain. J Immunol 2003, 171:1647-1651.

57. Uza N, Nakase H, Yamamoto S, Yoshino T, Takeda Y, Ueno S, Inoue S, Mikami S, Matsuura M, Shimaoka T, Kume N, Minami M, Yonehara S, Ikeuchi $\mathrm{H}$, Chiba T: SR-PSOX/CXCL16 plays a critical role in the progression of colonic inflammation. Gut 2011, 60:1494-1505.

58. Abel S, Hundhausen C, Mentlein R, Schulte A, Berkhout TA, Broadway N, Hartmann D, Sedlacek R, Dietrich S, Muetze B, Schuster B, Kallen KJ, Saftig P, Rose-John S, Ludwig A: The transmembrane CXC-chemokine ligand 16 is induced by IFN-gamma and TNF-alpha and shed by the activity of the disintegrin-like metalloproteinase ADAM10. J Immunol 2004, 172:6362-6372.

59. Hase K, Murakami T, Takatsu H, Shimaoka T, limura M, Hamura K, Kawano K, Ohshima S, Chihara R, Itoh K, Yonehara S, Ohno H: The membrane-bound chemokine CXCL16 expressed on follicle-associated epithelium and $\mathrm{m}$ cells mediates lympho-epithelial interaction in GALT. J Immunol 2006, 176:43-51.

60. Diegelmann J, Seiderer J, Niess J, Haller D, Goeke B, Reinecker H, Brand S: Expression and regulation of the chemokine CXCL16 in Crohn's disease and models of intestinal inflammation. Inflamm Bowel Dis 2010, 16:1871-1881

61. Hemmi H, Takeuchi O, Kawai T, Kaisho T, Sato S, Sanjo H, Matsumoto M, Hoshino K, Wagner H, Takeda K, Akira S: A Toll-like receptor recognizes bacterial DNA. Nature 2000, 408:740-745.

62. Krieg A: CpG motifs in bacterial DNA and their immune effects. Annu Rev Immunol 2002, 20:709-760

63. Yu D, Putta MR, Bhagat L, Li Y, Zhu F, Wang D, Tang JX, Kandimalla ER, Agrawal S: Agonists of Toll-like receptor 9 containing synthetic dinucleotide motifs. J Med Chem 2007, 50:6411-6418.

64. de Kivit S, van Hoffen E, Korthagen N, Garssen J, Willemsen LEM: Apical TLR ligation of intestinal epithelial cells drives a $T(h) 1$-polarized regulatory or inflammatory type effector response in vitro. Immunobiology 2011, 216:518-527.

65. Forsberg G, Hernell O, Melgar S, Israelsson A, Hammarstrom S, Hammarstrom ML: Paradoxical coexpression of proinflammatory and down-regulatory cytokines in intestinal T cells in childhood celiac disease. Gastroenterology 2002, 123:667-678

66. Salvati VM, Mazzarella G, Gianfrani C, Levings MK, Stefanile R, De Giulio B, laquinto G, Giardullo N, Auricchio S, Roncarolo MG, Troncone R: Recombinant human interleukin 10 suppresses gliadin dependent $T$ cell activation in ex vivo cultured coeliac intestinal mucosa. Gut 2005, 54:46-53.

67. Gianfrani C, Levings MK, Sartirana C, Mazzarella G, Barba G, Zanzi D, Camarca A, laquinto G, Giardullo N, Auricchio S, Troncone R, Roncarolo MG: Gliadin-specific type 1 regulatory T cells from the intestinal mucosa of treated celiac patients inhibit pathogenic T cells. J Immunol 2006, 177:4178-4186.

68. Nilsen EM, Lundin KEA, Krajci P, Scott H, Sollid LM, Brandtzaeg P: Gluten specific, Hla-Dq restricted T-cells from celiac mucosa produce cytokines with Thl or Th0 profile dominated by interferon-gamma. Gut 1995, 37:766-776.

69. Nilsen EM, Jahnsen FL, Lundin KEA, Johansen FE, Fausa O, Sollid LM, Jahnsen J, Scott H, Brandtzaeg P: Gluten induces an intestinal cytokine response strongly dominated by interferon gamma in patients with celiac disease. Gastroenterology 1998, 115:551-563.

70. Lahdenperä A, Ludvigsson J, Falth-Magnusson K, Högberg L, Vaarala O: The effect of gluten-free diet on Th1-Th2-Th3-associated intestinal immune responses in celiac disease. Scand J Gastroenterol 2011, 46:538-549.

doi:10.1186/1471-230X-13-113

Cite this article as: Cheng et al:: Duodenal microbiota composition and mucosal homeostasis in pediatric celiac disease. BMC Gastroenterology 2013 13:113.

\section{Submit your next manuscript to BioMed Central and take full advantage of:}

- Convenient online submission

- Thorough peer review

- No space constraints or color figure charges

- Immediate publication on acceptance

- Inclusion in PubMed, CAS, Scopus and Google Scholar

- Research which is freely available for redistribution 